International Journal on Intelligent Electronic Systems, Vol. 5, No.1, January 2011

\title{
SIMULATION AND HARMONIC ANALYSIS OF IMPEDANCE SOURCE INVERTER FED WIND DRIVEN SELF - EXCITED INDUCTION GENERATOR
}

\author{
Sasikumar M. ${ }^{1}$, Chenthur Pandian S. $^{2}$ \\ ${ }^{1}$ Department of EEE, Sathyabama University, Chennai, Tamilnadu, India. \\ ${ }^{2}$ Selvam College of Technology, Namakkal, Tamilnadu, India.
}

\begin{abstract}
This paper presents the simulation and harmonic analysis of impedance source inverter and multi level inverter for variable speed wind driven renewable energy conversion system. The output voltage of wind driven self excited induction generator (SEIG) is depending on the wind velocity fluctuations, self excitation capacitance value and load variations. The minimum and maximum values of the excitation capacitor banks to satisfies the reactive power burden requirements. The improved power electronic converters like impedance source inverter and multi level inverter are interface with the wind driven self - excited induction generator (SEIG). By controlling the shoot through state or boost factor of impedance source inverter (ZSI), the variable magnitude, variable frequency voltage of the induction generator can be controlled. The comparative analysis of this two inverters are discussed.
\end{abstract}

Keywords: Self - Excited Induction Generator (SEIG), Wind Turbine, Impedance Source Inverter (ZSI), Multi Level Inverter (MLI).

\section{INTRODUCTION}

Wind power generation is one of the most important and promising energy sources of renewable energy source. The potential of wind energy is very large. It has non-polluting, global safety and the quality of life. The wind speed of the wind driven SEIG is lies between $5 \mathrm{~km} / \mathrm{hr}$ to $20 \mathrm{~km} / \mathrm{hr}$. The seasonal variation of wind is maximum between the months of June September. The diurnal variation is very small during the month of July. The conversion of wind energy into mechanical energy by using the horizontal axis wind turbine [1].

The induction generator is used to generate electricity from the varying wind velocity conditions. The induction generators are brush less construction with squirrel - cage rotor, without DC supply for excitation, reliable, reduced maintenance and better transient performance [3]. The isolated wind power generation is also called stand-alone wind generation scheme. These schemes is used to supply power to pump water, grid grain and cut lumber applications. By using ZSI and $\mathrm{MLI}$ will be used to convert variable magnitude, variable frequency voltage into reliable constant voltage and constant frequency supply to drive the isolated load [4]. In remote areas, where the utility grid connected power system does not exist, so the stand-alone system can be used to satisfy the utility power. The output power of the SEIG is rectified using the diode bridge rectifier and the dc power is transferred to the load through a PWM inverter [1]. The even orders of harmonics are appeared across the rectifier output voltage. The smoothening series inductor is used to reduce the amplitude of ripple contents within the limits. The harmonic currents will lead to produce excessive heating in the connected load from inverter. The shunt capacitor filters are used to reduce reactive power compensation. By using the multi level inverters, the pulse number to be increased, so the harmonic present in the system is decreased. Both buck and boost operation can be made by using impedance source inverters [6]. The impedance source is act as a filter, the EMI noise to be increased. The harmonic distortion is reduced compared with the traditional inverters [5]. The output voltage of ZSI is mainly depends upon the shoot through states or boost factor. The two inductors of impedance source will induces high voltage, which appear across the two capacitors [7].

\section{PROPOSED SYSTEM DESCRIPTION}

A proposed ZSI based wind driven SEIG fed load is shown in fig. 1.1. The wind power generation system consisting of a wind turbine driven SEIG connected to the isolated load through an impedance source inverter. 


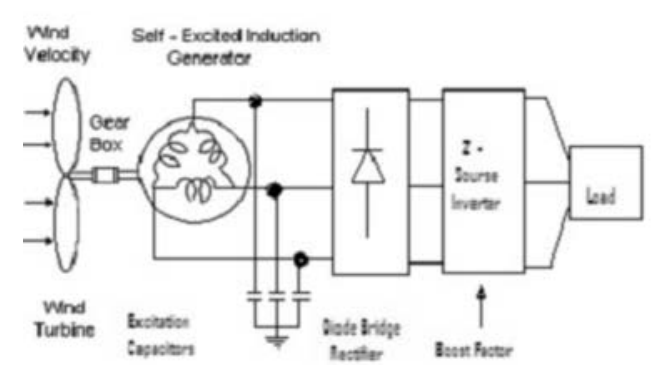

Fig. 1. Proposed Impedance Source Inverter based Wind Power Generation System

The power conversion efficiency of ZSI is improved compared to the traditional inverters for wind electric power generation. In traditional inverters, the upper and lower switches of each phase cannot be switched on simultaneously either by EMI noise [6]. The output voltage of the ZMI is limited to either greater or lesser then the given input voltage. The variable output voltage from the induction generator is rectified and then inverted by using the proposed inverter [7]. The ZSI can produce an output voltage greater than the input voltage by controlling the shoot through time To. This proposed scheme is used to improve the power factor and reduce harmonic current [3].

\section{A. Wind Turbine Characteristics}

The common wind turbine with a horizontal axis is simple in working principle and it will produce a electric power economically. The wind turbine rotor drives a induction generator through a step up gear box [1]. The wind power density is given by

$$
P W=0.5 \rho C p A V_{w}^{3}
$$

Where $\rho$ is the air density in $\mathrm{kg} / \mathrm{m}^{3} \quad C_{p}$ is expressed as a function of $\lambda$

$$
\lambda=\frac{R \omega s u b t}{V_{w}}
$$

Dimension less power co-efficient

$$
C_{p}=0.5\left[\frac{116}{\lambda_{1}}-0.4 \beta-5\right] e^{\frac{-16.5}{\lambda_{1}}}
$$

The energy content of the wind per square meter for any specified period is

$$
\begin{aligned}
& \text { Energy Content } \\
& =0.0107073 . \rho . \sum_{i=1}^{N_{m}} V_{i}^{3}{W h m^{-2}}^{-2} \\
& \text { 0.00001073. rho. } \sum_{i=1}^{N_{m}} V_{i}^{3} W h m^{-2}
\end{aligned}
$$

Where $V_{i}$ is the hourly wind speed in kmph for $i$ hour, $N_{m}$ is the total hours in the specified period. The maximum theoretical power co efficient is equal to 0.593 .

\section{B. Self - Excited Induction Generator Modeling}

The output power of the wind driven induction generator is determined by the operating speed. The per unit slip of the induction generator is lies between 0 and 0.05 . The dynamic characteristics behavior of self-excited induction generator can be represented by the electromechanical equation derived in the synchronously rotating $q-d$ reference frame [6]-[9]. The dynamic model of the induction machine is derived by using a two-phase motor in direct and quadrature axes [4].

$$
\begin{aligned}
& \pi_{q s}=-K_{1} r_{1} i_{q s}-\left(i_{q s} / C v_{d s}+K_{2} L_{m} w_{m}\right) i_{d s}+ \\
& K_{2} r_{2} i_{q r}-K_{1} L_{m} w_{m} i_{d r} \quad(6) \\
& \pi_{d s}=\left(i_{q s} / C v_{d s}+K_{2} L_{m} w_{m}\right) i_{q s}-K_{1} r_{1} i_{d s}+ \\
& K_{1} L_{m} w_{m} i_{q r}+K_{2} r_{2} i_{d r}-K_{1} v_{d s} \quad(7) \\
& \pi_{q r}=-K_{2} r_{1} i_{q s}+L_{1} K_{2} w_{m} i_{d s}-\left(r_{2}+K_{2} L_{m} r_{2}\right) L_{2} i_{q r}+ \\
& \left(K_{1} L_{1} w_{m}-i_{q s} / C v_{d s}+\right) i_{d r} \\
& \pi_{d r}=-L_{1} K_{2} w_{m} i_{q s}+K_{2} r_{1} i_{d s}-\left(L_{1} K_{1} w_{m}-I_{q s} / C v_{d s}\right) i_{q r}
\end{aligned}
$$

$$
+\left(r_{2}+K_{2} L_{m} r_{2}\right) L_{2} i_{d r}+K_{2} v_{d s}
$$

where

$$
K_{1}=\frac{L_{r}}{\left(L_{s} L_{r}-L_{m}^{2}\right)} \text { and }
$$




$$
K_{2}=\frac{L_{m}}{\left(L_{s} L_{r}-L_{m}^{2}\right)}
$$

The mechanical output power of the variable speed wind turbine is

$$
P_{m}=T_{m} \omega_{s} v
$$

Where $v=\frac{N}{N_{S}}$ is the per unit speed

$N$ and $N_{S}$ are the rotor speed and rated synchronous speed in rpm [6].

$T_{m}$ is the mechanical torque produced in N.m. Equations (6)-(9) are derived assuming that the $d$-axis is aligned with the stator terminal voltage phasor (i.e., $\left.V_{q s}=0\right)$ [5]. In self-excited induction generators, the magnitude of the generated air-gap voltage in the steady state equation is given by

$$
V_{g}=\omega_{e} L_{m}\left|i_{m}\right|
$$

Where

$$
\left|i_{m}\right|=\sqrt{\left(i_{q s}+i_{q r}\right)^{2}+\left(i_{d s}+i_{d r}\right)^{2}}
$$

The electromagnetic braking torque $T_{g}$ developed by the induction generator is expressed as

$$
T_{g}=-1.5\left(\text { Poles/2) Lm }\left(i_{q s} i_{d r}-i_{d s} i_{q r}\right)\right.
$$

Wind turbine and induction generator rotors are represented as a lumped mass.

$$
L_{m}^{\prime}=\frac{\sigma}{1-\sigma} L_{m}, \sigma=1-\frac{L_{m}^{2}}{L_{s} L_{r}}
$$

\section{Un Controlled Bridge Rectifier}

Three phase uncontrolled bridge rectifier is used to convert the variable voltage, variable frequency at the induction generator terminal into rectified dc voltage [3].

The output voltage is expressed as

$$
V_{r}=(3 \sqrt{2} / \pi)(\sqrt{3} / \sqrt{2}) * V_{d s} * n_{i}
$$

Input transformer's turn's ratio is $1: \eta$. The series reactor $(L)$ and shunt reactor $(C)$ acts as an input filter.
The current ripples and voltage ripples are reduced by using the above components [3].

\section{Multi Level Inverters}

The diode clamped multi level inverters are used to eliminate over voltage stress and reduce the switching frequency. By increasing the voltage levels of the inverter reduces the switching losses. To connecting the switching devices in parallel connections it leads to higher current levels. Multilevel converter topologies are based on this principle, and therefore the voltages applied to the devices can be controlled and limited. Then number of $\mathrm{H}$ bridges is formed as 4. The no of bridges is equivalent to $(m-1) / 2$ where $n$ is the no of levels (here 9) and the no of carrier waves for PWM control is equal to $(m-1)$ overall for the positive and negative gate pulse generators.

The modulation index of the inverter is

$$
\bar{m}=\frac{\sqrt{3}}{2} m \text {. The range of the modulation index is }
$$

$$
0 \leq m \leq \frac{2}{\sqrt{3}}
$$

\section{E. Z - Source Inverters}

The impedance network is a two-port network. This network also called as lattice network [5]. This lattice network consists of split inductors $\left(L_{1}\right.$ and $\left.L_{2}\right)$ and capacitors $\left(C_{1}\right.$ and $\left.C_{2}\right)$. The Impedance Source Inverter consists of rectifier output voltage source, impedance network, inverter connected with isolated load. By using shoot through duty cycle and modulation index can control the output voltage of the $Z$ source inverter. This is more effective to suppress voltage stress and reduce current ripples [7]. The Impedance Source Inverter Bridge has one extra zero state. The $Z$ source inverters are used to operate both buck and boost operation. The output voltage of $Z S I$ is mainly depends on the boost factor. The capacitors in the impedance network can provide stiff voltage stress across the inverter [6]. The capacitor voltage and input voltage of the $Z$ source inverter is

$$
V_{c}=\frac{1-D_{0}}{1-2 D_{0}} V_{0}
$$


Where $D_{0}$ is the shoot through duty ratio, $V_{0}$ is the diode rectifier output voltage. The output power can be expressed as

$$
P_{\text {out }}=\frac{3 p f}{\sqrt{2}} \hat{V} \text { phase I }
$$

Where $I$ is the rms load current. The current through the inverter during shoot through is twice of the inductor current.

\section{SIMULATION RESULTS}

The multi level inverter and impedance source inverter fed wind power conversion system is simulated using Matlab and the results are presented. The minimum and maximum values of the self-excitation capacitance requirement is previously [8]. The $d-q$ model of the self-excited induction generator is used to understand the all characteristics behavior of the generator system. The simulation model of the wind driven self-excited induction generator fed multi level inverter drive system and $Z$ - source inverter are shown in Fig 3.1 \& 3.7. The equivalent circuit parameters of the induction generators are required for modeling. The dynamic frequency of the induction generator

is calculated by using a three-axes to two-axes transformation. The multi level inverter configuration is shown in fig 3 . The generated output voltage is shown in Fig. 4. The generated output voltage is converted into dc voltage by using the diode bridge rectifier. The shunt capacitor is used to reduce the ripple content in the dc link voltage of the SEIG fed rectifier system. The line voltage and line current are shown in fig 5 and 6 respectively. Frequency spectrum is shown in Fig 7. THD value is $6.85 \%$. By adjusting the shoot through duty cycle with the restriction of $Z$ source inverter to keep the voltage across the switches not to exceed its limit. The generator output voltage is shown in Fig. 9. Line voltage and Line current are shown in Figs. 10 and 11 respectively. Frequency spectrum is shown in Fig 12. THD value is $4.94 \%$. Harmonic distortion is reduced at the output of $Z$ source inverter fed isolated system the THD is minimum with ZSI fed inverter system

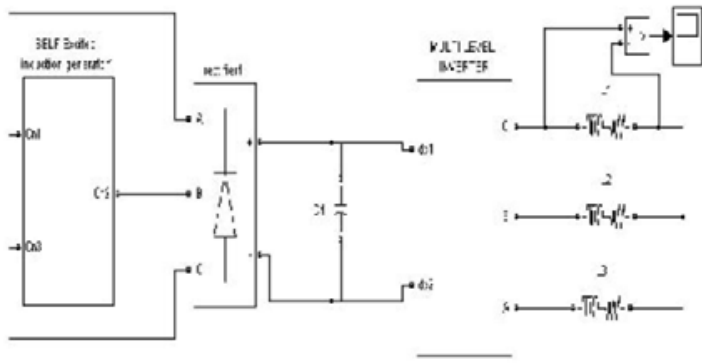

Fig. 2 Simulation Model SEIG with Multi Level Inverter fed R - L Load System

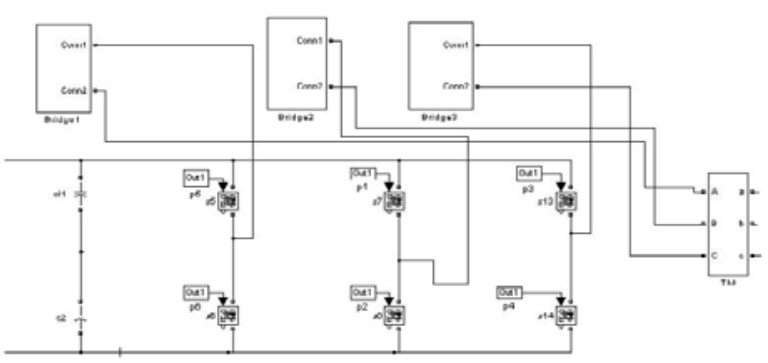

Fig. 3 Multi Level Inverter Configuration

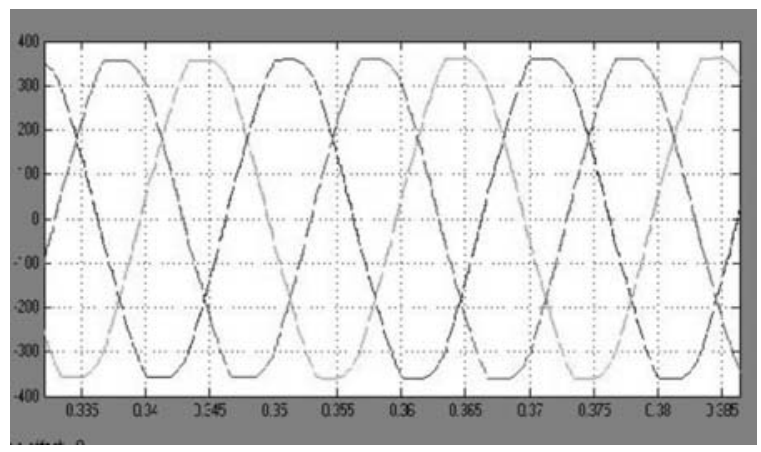

Fig. 4 Generated Output Voltage of SEIG

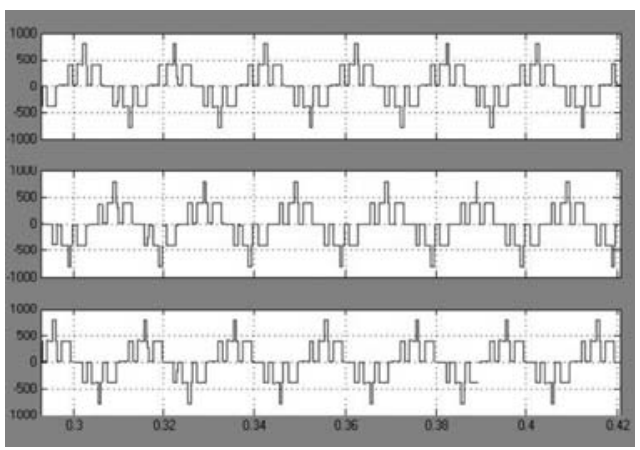

Fig. 5 Line Voltage of the SEIG with Multi level inverter fed WECS 


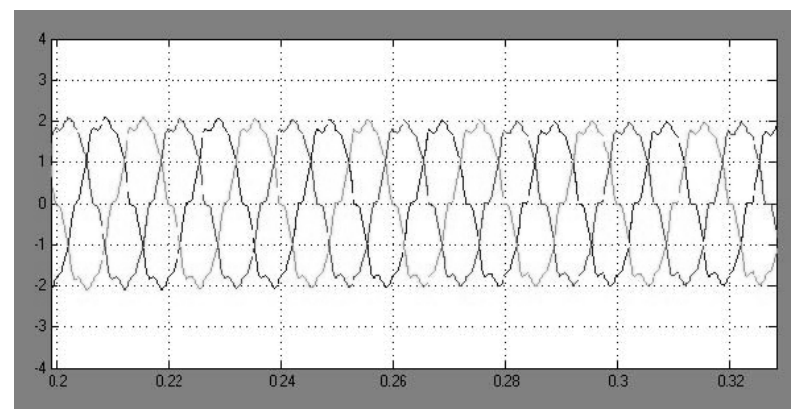

Fig. 6 Line Current of the SEIG with Multi level inverter fed WECS

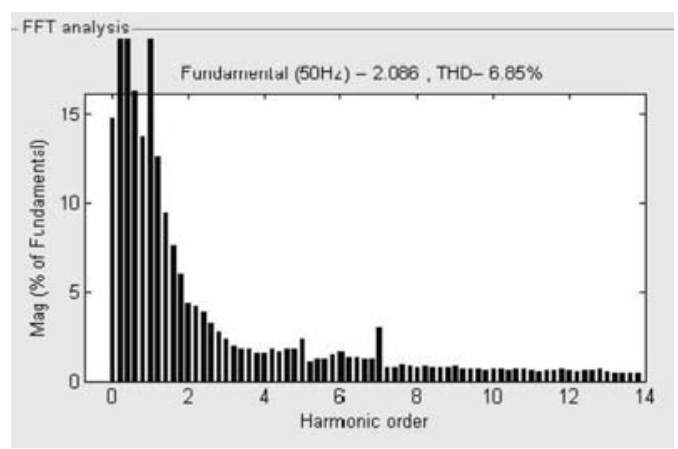

Fig. 7 FFT Analysis of the SEIG with Multi level inverter fed WECS

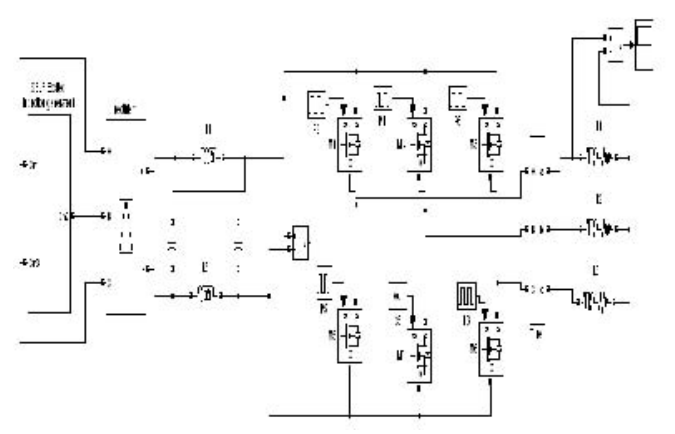

Fig. 8 Simulation Model of SEIG with Z Source Inverter fed Load System

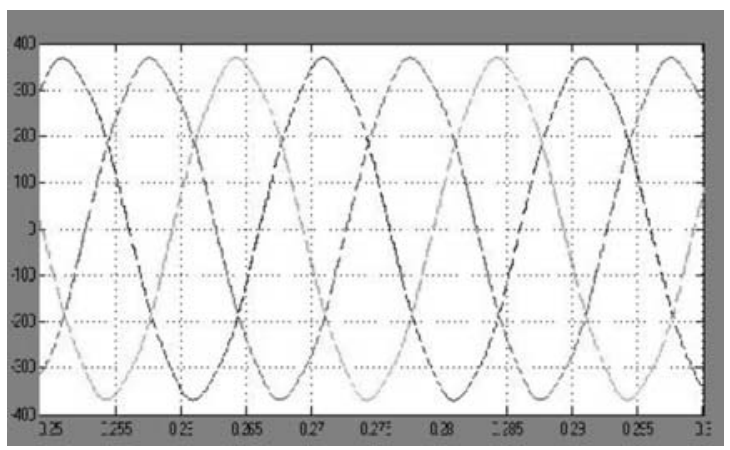

Fig. 9 Generator Voltage of SEIG

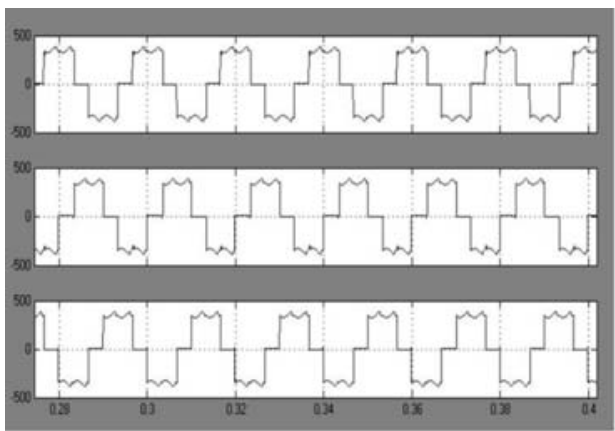

Fig. 10 3.4 Line Voltage of the SEIG with Z-Source Inverter fed WECS

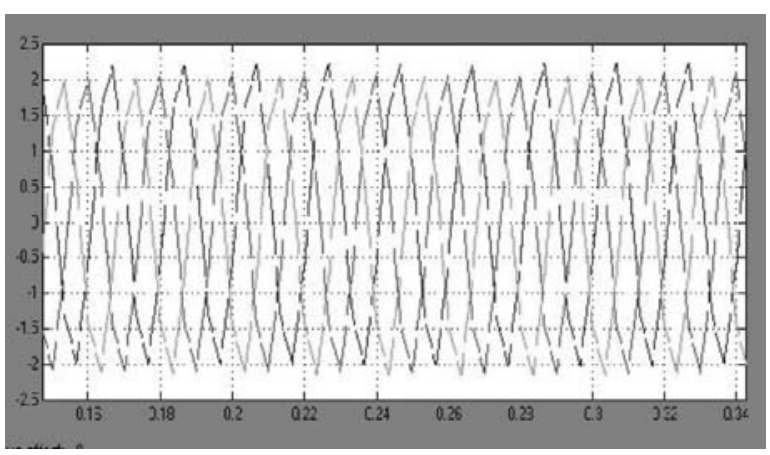

Fig. 11 Line Current of the SEIG with Z-Source Inverter fed WECS

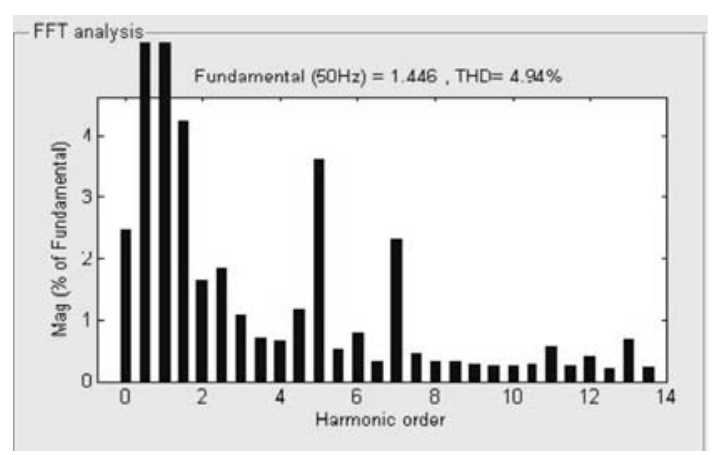

Fig. 12 FFT Analysis of the SEIG with Z - Source Inverter fed WECS

\section{CONCLUSION}

The multi level inverters and impedance source inverters fed wind driven self excited induction generator based energy conversion system results are presented and the total harmonic distortions factors are compared. The impedance network is used for both buck and boost operation. This network also acts as second order filter. Using the impedance source inverter compared with the multi level inverter fed drive system reduces the harmonic contents. 


\section{REFERENCES}

[1] Rohin M. Hilloowala and Adel M. Sharaf, "A Rule-Based Fuzzy Logic Controller for a PWM Inverter in a Stand alone Wind Energy Conversion Scheme" IEEE, Transaction on Industry Applications, Vol. 32.No.1 January/February 1996, pp 57-65.

[2] Li Wang, Chaing-Huei Lee, "A novel analysis on the performance of an Isolated self excited induction generators," IEEE Trans. on Energy conversion June 1993, vol.12, No.2.

[3] Rohin M.Hilluwala and Sharaf.A,M "Modeling, Simulation and Analysis of variable speed constant frequency wind energy conversion scheme using self excited induction generator," IEEE Trans. on Energy conversion, 1991.

[4] Natarajan.K, Sharaf.A, Sivakumar.S and Naganathan.S, "Modeling and control design for wind energy conversion scheme using self-excited induction generator," IEEE Trans. on Electron. Comput. Sept.1987 vol.2, No.3, pp. 506512.

[5] R. Bharanikumar, R. Senthilkumar, and A. Nirmal Kumar "Impedance Source Inverter for Wind Turbine Driven Permanent Magnet Generator", IEEE Trans. on Energy conversion, 2009.

[6] F. Z. Peng, "Z-Source inverter," IEEE Trans. Ind Applicat.,vol. 39, pp.504-510, Mar./Apr. 2003.

[7] F. Z. Peng, M. Shen, and Z. Qian, "Maximum boost control of the $Z$ source inverter," IEEE Transaction on Power Electronics. vol.20,no.4, pp833-838 July 2005.
[8] T.F. Chan." Capacitance requirements of self-excited induction generators ", IEEE Transactions on Energy Conversion, Vol. 8, No. 2, June 1993 pp 304-311.

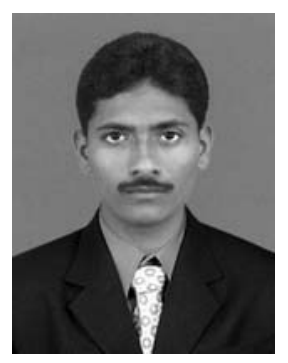

Sasikumar.M has received the B.E degree in Electrical and Electronics Engineering from K.S.Rangasamy College of Technology, Madras University, India in 1999, and the M.Tech degree in power electronics from VIT University, in 2006. Currently, he is Research Scholar in Sathyabama University, Chennai. His research interest is on wind energy systems.

Dr.S.Chenthur Pandian was born in Tamilnadu, India in 1959.

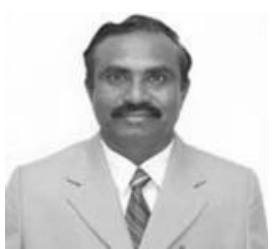
He was graduated from the institution of engineers, calcuta (India) and received his post graduate degree from Punjab University, Chandigarh (India). He has obtained his Ph.d. degree from periyar university, salem,

Tamilnadu, India.

Currently he is working as a Principal in Selvam College of Technology, Namakkal, and Tamilnadu, India. His research areas are power system, power electronics, neural network, fuzzy logic and Neuro fuzzy systems. He is a member of ISTE, IE \& IEEE. 